\title{
Highly Ordered Pt-Np Catalyst from Self-Assembly of Block Copolymer and Its Durability in Fuel Cell Application
}

\author{
Xi Yang ${ }^{1,2}$, Jianguo Duan ${ }^{1}$, Yingjie Zhang ${ }^{1, *}$, Peng Dong ${ }^{1, *}$, Dan Su $^{2}$, Mingyu Zhang $^{2}$ \\ ${ }^{1}$ Faculty of Metallurgical and Energy Engineering, Kunming University of Science and Technology, \\ Kunming 650093, China; \\ ${ }^{2}$ Yunnan Provincial Energy Research Institute Co. Ltd, Kunming 650599, China \\ *E-mail: dongpeng2001 @ 126.com
}

doi: $10.20964 / 2019.07 .58$

Received: 11 March 2019/ Accepted: 30 April 2019 / Published: 10 June 2019

\begin{abstract}
Employing platinum-nanoparticle (Pt-Np) arrays with highly ordered and uniform arrangements of Nps in fuel cell is a possible approach to reduce the Pt-Np aggregation and improve catalyst durability during catalyst functioning. While the current methodologies for Pt-Np catalysts' synthesis can hardly achieve the homogeneously distributed Pt-Np layer due to the difficulty of control over the growing/located sites of Pt Nps precisely on carbon supporters. In this work, highly uniform and ordered Pt-Np arrays supported on carbon paper are prepared by pattern formation based on the self-assembly of PS-P2VP block copolymers (BCs). Cyclic voltammetry (CV) test of the arrays and the endurance test of the corresponding fuel cell indicate that, due to the absence of the Pt-Np aggregation, no significant performance loss is caused after 10000 cycles of CV and 100-hour running of the fuel cell. The aggregation can be successfully overcome by the quasi-homogeneous spacing distribution, which leads to higher electrocatalytic stability and better catalyst durability compared to the commonly used Johnson Matthey Pt/C commercial catalyst with the same Pt loading. After the endurance test, the Pt-Np arrays show almostly invariable size and spacing distributions, it has great potential in improving fuel-cell lifetime. The $\mathrm{BC}$ route is a promising strategy to achieve ultra-long-life and high- efficient functioning of the fuel cell.
\end{abstract}

Keywords: Pt-NP arrays, Spacing distribution, BC route, Cathodic catalysts, Fuel cell

\section{FULL TEXT}

(C) 2019 The Authors. Published by ESG (www.electrochemsci.org). This article is an open access article distributed under the terms and conditions of the Creative Commons Attribution license (http://creativecommons.org/licenses/by/4.0/). 